\title{
Trajetórias Relacionais e Reprodutivas Conducentes à Gravidez na Adolescência: a Realidade Nacional e Regional Portuguesa
}

\author{
Relational and Reproductive Trajectories Leading to Adolescent Pregnancy in \\ Portugal: a National and Regional Characterization
}

Raquel PIRES ${ }^{1,2}$, Joana PEREIRA ${ }^{1,2}$, Anabela Araújo PEDROSA
Maria Cristina CANAVARRO ${ }^{1,2}$ Acta Med Port 2014 Sep-Oct;27(5):543-555

\section{RESUMO}

Introdução: Este estudo pretendeu caracterizar as trajetórias relacionais e reprodutivas conducentes à gravidez na adolescência em Portugal, explorando a existência de especificidades regionais.

Material e Métodos: O estudo decorreu entre 2008 e 2013 em 42 serviços de saúde públicos. A amostra, nacionalmente representativa, incluiu 459 grávidas com idades entre os 12 e os 19 anos. Os dados foram obtidos por autorrelato, através de uma ficha de caracterização construída para o efeito.

Resultados: Independentemente de terem tido um $(59,91 \%)$ ou múltiplos parceiros sexuais $(40,09 \%)$, as adolescentes engravidaram de forma mais frequente numa relação de namoro, utilizando contraceção à data da conceção e tendo identificado a falha contracetiva que esteve na origem da gravidez (39,22\%). A nível regional, outras trajetórias surgiram com elevada prevalência, refletindo opções como a decisão de engravidar (Alentejo/Açores), a não utilização de contraceção (Centro/Madeira) ou a sua utilização ineficaz sem que a falha contracetiva fosse identificada (Madeira). As relações de namoro revelaram-se maioritariamente duradouras ( $>19$ meses), com homens mais velhos ( $>4$ anos) e fora do sistema de ensino $(75,16 \%)$; estes resultados foram particularmente expressivos quando a gravidez foi planeada.

Discussão: O conhecimento gerado por este estudo reflete a necessidade de investir em abordagens preventivas que atendam às necessidades específicas das jovens de cada região e integrem a população masculina de maior risco.

Conclusão: Os nossos resultados podem contribuir para o delineamento de políticas de saúde mais eficazes e para uma atuação multidisciplinar mais informada ao nível da educação sexual e do planeamento familiar nas diferentes regiões do país.

Palavras-chave: Adolescente; Contraceção; Educação Sexual; Gravidez na Adolescência; Planeamento Familiar.

\section{ABSTRACT}

Introduction: The current study aimed to describe the relational and reproductive trajectories leading to adolescent pregnancy in Portugal, and to explore whether there were differences in this process according to adolescents' place of residence.

Material and Methods: Data were collected between 2008 and 2013 in 42 public health services using a self-report questionnaire developed by the researchers. The sample consisted of a nationally representative group of pregnant adolescents $(n=459)$.

Results: Regardless of having had one $(59.91 \%)$ or multiple sexual partners $(40.09 \%)$, the majority of adolescents became pregnant in a romantic relationship, using contraception at the time of the conception and knowing the contraceptive failure which led to pregnancy (39.22\%). In some regions other trajectories were highly prevalent, reflecting options such as planning the pregnancy (Alentejo Region/ Azores Islands), not using contraception (Centro Region/Madeira Islands) or using it incorrectly, without identifying the contraceptive failure (Madeira Islands). On average, romantic relationships were longer than 19 months and adolescents' partners were older than themselves (> 4 years) and no longer in school $(75.16 \%)$; these results were particularly significant when the pregnancy was planned. Discussion: The knowledge gained in this study shows that prevention efforts must be targeted according to the adolescents' needs in each region and should include high-risk male groups.

Conclusion: Our results may enable more efficient health policies to prevent adolescent pregnancy in different country regions and support educators and health care providers on sexual education and family planning efforts.

Keywords: Adolescent; Contraception; Sex Education; Pregnancy in Adolescence; Portugal.

\section{INTRODUÇÃo}

A gravidez na adolescência não é um fenómeno inevitavelmente adverso do ponto de vista físico ou mental. ${ }^{1-3}$ No entanto, muitas vezes como resultado das desfavoráveis condições socioeconómicas em que ocorre, ${ }^{4,5}$ a gravidez na adolescência tem sido associada a um maior risco de parto pré-termo, ${ }^{6-9}$ nascimento de bebés de baixo peso $0^{6,79}$ e depressão materna.$^{10}$ Acresce que, nas últimas décadas, mudanças sociais contribuíram para uma visão da gravidez na adolescência como cada vez mais inoportuna e indesejável, colocando crescentes desafios no âmbito do planeamento familiar com adolescentes em diversos países desenvolvidos. ${ }^{5,9,11,12}$ Em Portugal, a taxa de nascimentos em mães com menos de 20 anos sofreu um decréscimo acentuado e consistente ao longo das últimas décadas. No ano de 1981 , estes nascimentos perfaziam $11,1 \%$ do total de nascimentos do país; em 2001, esta taxa encontrava-se

1. Faculdade de Psicologia e de Ciências da Educação. Universidade de Coimbra. Coimbra. Portugal.

2. Unidade de Intervenção Psicológica. Maternidade Daniel de Matos. Centro Hospitalar e Universitário de Coimbra. Coimbra. Portugal.

3. Serviço de Obstetrícia. Maternidade Daniel de Matos. Centro Hospitalar e Universitário de Coimbra. Coimbra. Portugal.

4. Associação Para o Planeamento da Família. Lisboa. Portugal.

5. Centro Lusíada de Investigação em Serviço Social e Intervenção Social. Universidade Lusíada de Lisboa. Lisboa. Portugal.

6. Divisão de Saúde Sexual, Reprodutiva, Infantil e Juvenil. Direção-Geral da Saúde. Lisboa. Portugal.

Recebido: 11 de Outubro de 2013 - Aceite: 27 de Janeiro de 2014 | Copyright @ Ordem dos Médicos 2014 
reduzida para $6,1 \%$. Desde então, verificou-se um decréscimo médio anual entre os $0,2 \%$ e os $0,3 \%$, que se manteve constante mesmo após a despenalização da interrupção voluntária da gravidez, por opção da mulher, quando realizada nas 10 primeiras semanas de gravidez (IVG). ${ }^{13}$ Desde 2009, verificou-se, aliás, uma tendência igualmente decrescente da taxa de IVG entre adolescentes. ${ }^{14-17}$ No entanto, os últimos dados oficiais, referentes ao ano de 2012 , situam a taxa de nascimentos em mães adolescentes nos $3,7 \%,{ }^{13}$ valor ainda preocupante, quer por se situar acima da média da União Europeia, ${ }^{11,12}$ quer por refletir uma evolução heterogénea nas diferentes regiões do país. ${ }^{13}$

A literatura tem salientado a diversidade de acontecimentos e decisões que podem conduzir as adolescentes à gravidez. Além da iniciação sexual - transição normativa na adolescência ${ }^{18}$ - tais acontecimentos e decisões passam por opções relativas ao planeamento da gravidez, à decisão contracetiva e ao comportamento contracetivo implementado. 5,19-22 No entanto, o risco de gravidez parece residir, não apenas em cada um destes acontecimentos e decisões separadamente - como têm sido abordados pela maioria dos estudos -, mas igualmente nas diferentes combinações entre eles e nos contextos relacionais que lhes estão subjacentes. Tal facto sugere a existência de uma

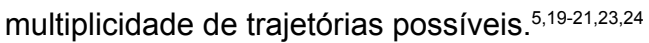

O planeamento da gravidez, em particular, tem sido pouco explorado na compreensão do comportamento contracetivo das adolescentes, nomeadamente por ser nesta faixa etária que ocorre um maior número de gravidezes não planeadas ${ }^{25,26}$ e por estas se encontrarem habitualmente associadas na população geral a um maior risco obstétrico do que as gravidezes planeadas. ${ }^{26}$ No entanto, diversos autores têm chamado a atenção para a necessidade de avaliar a decisão de engravidar nas investigações com adolescentes. ${ }^{22,27-29}$ Segundo Sheeder, Tocce e Stevens-Simon, ${ }^{29}$ por exemplo, contrariamente ao que se verifica em mulheres adultas, o planeamento da gravidez em adolescentes não se associa a melhores cuidados pré-natais nem a meIhores resultados obstétricos, devendo constituir motivo de preocupação. Em Portugal, apesar da escassez de dados nacionais posteriores a $1997,{ }^{26}$ investigações regionalmente circunscritas revelam que $30 \%$ das grávidas adolescentes estudadas nos Açores ${ }^{4}$ e $15 \%$ e $27 \%$ das inquiridas no Norte e no Sul do país planearam a gravidez. ${ }^{30}$ Num trabaIho recente, baseado numa amostra nacionalmente representativa de grávidas adolescentes, verificou-se que cerca de $22 \%$ das gravidezes foram planeadas. ${ }^{22}$ No entanto, o mesmo estudo revela que a proporção de gravidezes planeadas no Alentejo ultrapassou os $38 \%$. Estudos internacionais concluem ainda que a repetição da gravidez nesta fase do ciclo de vida se encontra muitas vezes associada ao planeamento de gravidezes consecutivas. ${ }^{31}$

Quanto à decisão contracetiva, entre todas as mulheres dos 15 aos 49 anos com possibilidade de engravidar, são as adolescentes que apresentam taxas mais baixas de utilização de métodos contracetivos. ${ }^{32}$ Nos Açores, a não utilização de contraceção parece relacionar-se maioritaria- mente com o facto de as adolescentes não gostarem dos métodos disponíveis ou considerarem que a sua utilização prejudica a relação, com o desejo de engravidar e com a ausência de informação sobre contraceção. ${ }^{4}$ Não são do nosso conhecimento, no entanto, dados relativos às restantes regiões do país. Pires et $a^{22}$ referem ainda que $71 \%$ das grávidas adolescentes da sua amostra que não planearam a gravidez reportam o uso de contraceção à data da conceção, sugerindo, de forma congruente com outros estudos, que a ocorrência de falhas contracetivas (e.g., uso inadequado/descontinuado dos métodos disponíveis) pode também estar na origem destas gravidezes. ${ }^{22-24,33-35}$ Os autores não disponibilizam, no entanto, informação sobre o tipo de falhas. Acresce que Carvalho ${ }^{30}$ e Pires et $\mathrm{al}^{22}$ sugerem a existência de especificidades regionais ao nível dos comportamentos contracetivos que conduzem as adolescentes à gravidez. Segundo o mais recente destes estudos, a ausência de contraceção foi mais frequente no Centro, nos Açores e no Algarve e foi em Lisboa e Vale do Tejo (LVT) e no Alentejo que as jovens menos identificaram a falha contracetiva que esteve na origem da gravidez. ${ }^{22}$

Relativamente aos contextos relacionais subjacentes a estes acontecimentos e decisões, o envolvimento com múltiplos parceiros sexuais tem sido considerado de risco para comportamentos contracetivos desadequados, ${ }^{28}$ assim como as relações ocasionais, quando comparadas com as relações de namoro. ${ }^{36}$ No entanto, estudos nacionais revelam a inexistência de diferenças no número de parceiros entre adolescentes grávidas e sem história de gravidez residentes em Portugal continental ${ }^{30}$ e concluem que apenas $2 \%$ das gravidezes ocorreram numa relação ocasional. ${ }^{22}$ As relações de namoro mais duradouras ${ }^{37}$ e com homens mais velhos parecem ser as que maioritariamente conduzem as adolescentes à gravidez. ${ }^{4,22,30,38}$ Estes parceiros são habitualmente adultos com baixas habilitações literárias, ou adolescentes mais velhos que abandonaram o sistema de ensino. 4,30,38-40 Segundo alguns autores, o envolvimento das adolescentes com tais parceiros parece associar-se particularmente ao planeamento da gravidez. ${ }^{31}$ William, no entanto, refere que parceiros com estas características têm um menor conhecimento sobre contraceção, o que poderá contribuir para a ineficácia da prevenção de gravidezes não planeadas. ${ }^{41}$ Não obstante, os autores concordam com a propensão destes homens para se envolverem em relações de elevada proximidade, apresentarem visões tradicionais dos papéis de género e percecionarem o nascimento de um filho como tendo um impacto reduzido na sua vida. ${ }^{31,39,41}$

Com base nestas evidências, e uma vez que não são do nosso conhecimento investigações que incorporem a compreensão das diferentes sequências de acontecimentos e decisões que podem conduzir as adolescentes à gravidez $e$ dos contextos relacionais a eles subjacentes, o objetivo do presente estudo foi caracterizar as trajetórias relacionais e reprodutivas conducentes à gravidez na adolescência em Portugal, averiguando a existência de especificidades regionais. 


\section{MATERIAL E MÉTIDOS}

Os dados foram recolhidos entre 2008 e 2013 em 42 serviços de saúde públicos, mediante aprovação das respetivas Comissões de Ética. A amostra, nacionalmente representativa, foi constituída por 459 grávidas adolescentes, com idades entre os 12 e os 19 anos, ${ }^{42}$ residentes em todas as regiões de Portugal (NUTS II; 2002) e com compreensão da língua portuguesa adequada ao preenchimento do protocolo de avaliação.

As adolescentes foram convidadas a participar durante o seu seguimento obstétrico; as que acederam colaborar assinaram um formulário de consentimento informado e responderam a uma ficha de caracterização construída para o efeito, sob a supervisão de um assistente de investigação. Quando as participantes tinham menos de 18 anos, os seus representantes legais assinaram igualmente o formulário de consentimento.

A ficha de caracterização foi construída a partir da entrevista semiestruturada utilizada na Unidade de Intervenção Psicológica da Maternidade Daniel de Matos para triagem das utentes da Consulta de Grávidas Adolescentes ${ }^{43}$ e incluiu perguntas de resposta aberta e fechada. As variáveis incluídas nas trajetórias relacionais e reprodutivas que conduziram à gravidez foram avaliadas através das perguntas 'Com quantos parceiros já teve relações sexuais?' (um vs. múltiplos parceiros sexuais), 'Tem uma relação de namoro [com o pai do bebé]? [Se relação inexistente] por favor indique [se] foi uma relação ocasional (relação de namoro vs. relação ocasional)', 'A gravidez foi planeada para o momento atual?' (gravidez planeada vs. gravidez não planeada), 'Utilizava algum método contracetivo?' (utilizava contraceção vs. não utilizava contraceção), '[Se utilizava,] o que falhou?' (identifica falha vs. não identifica falha). Quando as jovens não identificaram a falha contracetiva, a sua resposta à pergunta 'Quais [os métodos contracetivos utilizados]?' foi utilizada para codificar a ausência de identificação da falha de acordo com o método que estava a ser utilizado (e.g. Não identifica falha no uso do preservativo).

A análise estatística foi realizada com recurso ao software SPSS, v. 17. Com propósitos de caracterização, calculámos estatísticas descritivas (frequências, médias e desvios-padrão). Para calcular diferenças regionais relativamente às variáveis categoriais e contínuas, recorremos a testes de Qui-Quadrado (com correção de Monte Carlo quando a frequência esperada em alguma célula fosse menor que cinco) e a testes de Kruskal-Wallis (com testes post hoc $U$ de Mann-Whitney e respetiva correção de Bonferroni), respetivamente; foi ainda estimada a magnitude dos efeitos significativos observados, através do cálculo das estatísticas $V$ de Cramer e $r$ (efeitos pequenos $\geq 0,10$; efeitos médios $\geq 0,30$; efeitos grandes $\geq 0,50)$. ${ }^{44,45}$ As variáveis dicotómicas relativas a acontecimentos e decisões que pudessem estar na origem da gravidez e aos contextos relacionais que lhes estavam subjacentes foram incluídas nas trajetórias de acordo com o critério da sequência temporal entre as mesmas. As variáveis categoriais com mais de duas categorias ou contínuas referentes a característi- cas dos namorados e da relação que conduziu à gravidez foram posteriormente analisadas de acordo com a sua distribuição por trajetória identificada.

\section{RESULTADOS}

Como se pode observar na Tabela 1, as participantes eram na sua maioria caucasianas, pertenciam a níveis socioeconómicos baixos e residiam em localidades urbanas; maioritariamente solteiras, encontravam-se de forma frequente fora do sistema de ensino e desempregadas, reportaram uma escolaridade média de 8 anos, vivenciaram a menarca com uma idade média de 12 anos e iniciaram a vida sexual em média 3 anos depois. A idade gestacional variou entre as 5 e as 40 semanas, tratando-se da primeira gravidez para a maioria das adolescentes. Apenas numa minoria das situações a gravidez era múltipla ou foram reportadas complicações obstétricas. Contrariamente às restantes regiões do país, no Alentejo e nos Açores as adolescentes residiam maioritariamente em localidades semiurbanas/rurais e encontravam-se, juntamente com as jovens do Algarve, maioritariamente casadas/unidas de facto. Nos Açores e na Madeira todas as adolescentes eram caucasianas, enquanto nas restantes regiões 3,57\% a $35,29 \%$ das jovens pertenciam a minorias étnicas. As adolescentes dos Açores eram mais velhas do que as do Centro $(U=2091,00 ; p=0,011)$ e de LVT $(U=3638,00$; $p=0,002)$ e possuíam menores habilitações literárias do que as do Norte $(U=2745,00 ; p=0,001)$, Centro $(U=1869,50 ; p=0,005)$ e LVT $(U=3228,50 ; p=0,004)$. A história prévia de gravidez foi mais frequente no Alentejo e apenas na Madeira todas as jovens se encontravam a vivenciar a primeira gravidez. A história prévia de parto foi mais frequente no Alentejo e nos Açores. As adolescentes de LVT $(U=5800,00, p=0,014)$, do Alentejo $(U=533,00$, $p=0,004)$ e dos Açores $(U=2902,50 ; p=0,003)$ reportaram idades gestacionais mais avançadas do que as adolescentes do Norte.

Tal como representado na Fig. 1, verificámos um total de doze trajetórias conducentes à gravidez. A primeira e segunda trajetórias mais frequentes incluíram adolescentes que engravidaram do seu primeiro parceiro sexual (trajetória 3) ou após múltiplos parceiros (trajetória 10), numa relação de namoro, não tendo planeado a gravidez, usando contraceção à data da conceção e tendo identificado a faIha contracetiva que esteve na origem da gravidez. A terceira trajetória mais frequente incluiu adolescentes que engravidaram do seu primeiro parceiro, numa relação de namoro e tendo planeado a gravidez (trajetória 1). A quarta e quinta trajetórias incluíram adolescentes que engravidaram do seu primeiro parceiro (trajetória 2) ou após múltiplos parceiros (trajetória 11), numa relação de namoro, não tendo planeado a gravidez, mas não usando contraceção. A sexta e sétima trajetórias incluíram adolescentes que engravidaram do seu primeiro parceiro (trajetória 4) ou após múltiplos parceiros (trajetória 9), numa relação de namoro, não tendo planeado a gravidez, usando contraceção, mas não tendo identificado a falha contracetiva. A oitava trajetória 
Tabela 1 - Caracterização da amostra em estudo: variáveis sociodemográficas e clínicas (continua)

\begin{tabular}{|c|c|c|c|c|c|c|}
\hline & $\begin{array}{l}\text { Nacional } \\
(n=459)\end{array}$ & $\begin{array}{c}\text { Norte } \\
(n=112)\end{array}$ & $\begin{array}{l}\text { Centro } \\
(n=76)\end{array}$ & $\begin{array}{c}\text { LVT } \\
(n=135)\end{array}$ & $\begin{array}{l}\text { Alentejo } \\
(n=17)\end{array}$ & $\begin{array}{l}\text { Algarve } \\
(n=34)\end{array}$ \\
\hline & $n(\%)$ & $n(\%)$ & $n(\%)$ & $n(\%)$ & $n(\%)$ & $n(\%)$ \\
\hline $\begin{array}{l}\text { Idade } \\
\qquad M(D P) \\
\text { amplitude }\end{array}$ & $\begin{array}{c}16,43(1,26) \\
12-19\end{array}$ & $\begin{array}{c}16,48(1,19) \\
13-19\end{array}$ & $\begin{array}{c}16,21(1,41) \\
12-19\end{array}$ & $\begin{array}{c}16,28(1,11) \\
13-19\end{array}$ & $\begin{array}{c}16,76(1,56) \\
14-19\end{array}$ & $\begin{array}{c}16,32(1,20) \\
14-18\end{array}$ \\
\hline $\begin{array}{l}\text { Etnia } \\
\text { Caucasianas } \\
\text { Minorias étnicas }\end{array}$ & $\begin{array}{c}384(83,66) \\
75(16,34)\end{array}$ & $\begin{array}{c}108(96,43) \\
4(3.57)\end{array}$ & $\begin{array}{l}61(80,26) \\
15(19,74)\end{array}$ & $\begin{array}{l}96(71,11) \\
39(28,89)\end{array}$ & $\begin{array}{c}12(70,59) \\
5(29,41)\end{array}$ & $\begin{array}{l}22(64,71) \\
12(35,29)\end{array}$ \\
\hline $\begin{array}{l}\text { NSE }{ }^{\dagger} \\
\text { Baixo } \\
\text { Médio/Alto }\end{array}$ & $\begin{array}{r}425(92,56) \\
34(7,44)\end{array}$ & $\begin{array}{c}106(94,64) \\
6(5,36)\end{array}$ & $\begin{array}{c}69(90,79) \\
7(9,21)\end{array}$ & $\begin{array}{c}121(89,63) \\
14(10,37)\end{array}$ & $\begin{array}{c}16(94,12) \\
1(5,88)\end{array}$ & $\begin{array}{c}30(88,24) \\
4(11,74)\end{array}$ \\
\hline $\begin{array}{l}\text { Residência }^{\ddagger} \\
\text { Urbana } \\
\text { Semiurbana/Rural }\end{array}$ & $\begin{array}{l}331(72,11) \\
128(27,89)\end{array}$ & $\begin{array}{l}89(79,46) \\
23(20,54)\end{array}$ & $\begin{array}{l}38(50,00) \\
38(50,00)\end{array}$ & $\begin{array}{c}133(98,52) \\
2(1,48)\end{array}$ & $\begin{array}{l}8(47,06) \\
9(52,94)\end{array}$ & $\begin{array}{c}28(82,35) \\
6(17,65)\end{array}$ \\
\hline $\begin{array}{l}\text { Estado civil } \\
\text { Solteira } \\
\text { Unidas de facto/Casadas }\end{array}$ & $\begin{array}{l}266(57,95) \\
193(42,05)\end{array}$ & $\begin{array}{l}92(82,14) \\
20(17,86)\end{array}$ & $\begin{array}{l}38(50,00) \\
38(50,00)\end{array}$ & $\begin{array}{l}88(65,19) \\
47(34,81)\end{array}$ & $\begin{array}{c}5(29,41) \\
12(70,59)\end{array}$ & $\begin{array}{l}12(35,29) \\
22(64,71)\end{array}$ \\
\hline $\begin{array}{l}\text { Situação profissional } \\
\text { Estudante } \\
\text { Empregada } \\
\text { Desempregada }\end{array}$ & $\begin{array}{c}175(38,13) \\
37(8,06) \\
247(53,81)\end{array}$ & $\begin{array}{l}41(36,61) \\
13(11,61) \\
58(51,78)\end{array}$ & $\begin{array}{c}28(36,84) \\
9(11,84) \\
39(51,32)\end{array}$ & $\begin{array}{c}61(45,19) \\
8(5,93) \\
66(48,88)\end{array}$ & $\begin{array}{c}4(23,53) \\
1(5,88) \\
12(70,59)\end{array}$ & $\begin{array}{c}13(38,24) \\
1(2,94) \\
20(58,82)\end{array}$ \\
\hline $\begin{array}{l}\text { Escolaridade } \\
M(D P) \\
\text { amplitude }\end{array}$ & $\begin{array}{c}7,89(2,20) \\
0-12\end{array}$ & $\begin{array}{c}8,26(2,1) \\
2-12\end{array}$ & $\begin{array}{c}7,99(2,49) \\
0-12\end{array}$ & $\begin{array}{c}8,06(1,96) \\
3-12\end{array}$ & $\begin{array}{c}7,19(2,71) \\
1-11\end{array}$ & $\begin{array}{c}7,13(2,47) \\
1-11\end{array}$ \\
\hline $\begin{array}{l}\text { Idade da menarca } \\
M(D P) \\
\text { amplitude }\end{array}$ & $\begin{array}{c}11,86(1,47) \\
8-16\end{array}$ & $\begin{array}{c}11,83(1,34) \\
8-15\end{array}$ & $\begin{array}{c}11,49(1,39) \\
9-15\end{array}$ & $\begin{array}{c}11,87(1,44) \\
8-15\end{array}$ & $\begin{array}{c}12,59(1,84) \\
9-16\end{array}$ & $\begin{array}{c}11,88(1,54) \\
9-16\end{array}$ \\
\hline $\begin{array}{l}\text { Idade de iniciação sexual } \\
M(D P) \\
\text { amplitude }\end{array}$ & $\begin{array}{c}14,76(1,25) \\
11-19\end{array}$ & $\begin{array}{c}14,79(1,15) \\
12-17\end{array}$ & $\begin{array}{c}14,54(1,25) \\
12-17\end{array}$ & $\begin{array}{c}14,75(1,12) \\
11-19\end{array}$ & $\begin{array}{c}14,88(1,15) \\
13-17\end{array}$ & $\begin{array}{c}14,65(1,20) \\
12-17\end{array}$ \\
\hline $\begin{array}{l}\text { Gravidez prévia } \\
\text { Não } \\
\text { Sim } \\
\text { Missings }\end{array}$ & $\begin{array}{c}402(87,58) \\
56(12,20) \\
1(0,22)\end{array}$ & $\begin{array}{c}103(91,96) \\
9(8,04) \\
0(0,00)\end{array}$ & $\begin{array}{c}65(85,53) \\
11(14,47) \\
0(0,00)\end{array}$ & $\begin{array}{c}115(85,19) \\
20(14,81) \\
0(0,00)\end{array}$ & $\begin{array}{c}11(64,71) \\
5(29,41) \\
1(5,88)\end{array}$ & $\begin{array}{c}33(97,06) \\
1(2,94) \\
0(0,00)\end{array}$ \\
\hline $\begin{array}{l}\text { IVG prévia } \\
\text { Não } \\
\text { Sim } \\
\text { Missings }\end{array}$ & $\begin{array}{c}435(94,77) \\
23(5,01) \\
1(0,22)\end{array}$ & $\begin{array}{c}109(97,32) \\
3(2,68) \\
0(0,00)\end{array}$ & $\begin{array}{l}73(96,05) \\
3(3,95) \\
0(0,00)\end{array}$ & $\begin{array}{c}124(91,85) \\
11(8,15) \\
0(0,00)\end{array}$ & $\begin{array}{c}13(76,47) \\
3(17,65) \\
1(5,88)\end{array}$ & $\begin{array}{c}33(97,06) \\
1(2,94) \\
0(0,00)\end{array}$ \\
\hline $\begin{array}{l}\text { Parto prévio } \\
\text { Não } \\
\text { Sim } \\
\text { Missings }\end{array}$ & $\begin{array}{c}436(94,98) \\
21(4,58) \\
2(0,44)\end{array}$ & $\begin{array}{c}111(99,11) \\
1(0,89) \\
0(0,00)\end{array}$ & $\begin{array}{c}69(90,79) \\
7(9,21) \\
0(0,00)\end{array}$ & $\begin{array}{c}131(97,04) \\
4(2,96) \\
0(0,00)\end{array}$ & $\begin{array}{c}14(82,36) \\
2(11,76) \\
1(5,88)\end{array}$ & $\begin{array}{c}33(97,06) \\
1(2,94) \\
0(0,00)\end{array}$ \\
\hline $\begin{array}{l}\text { Idade gestacional } \\
M(D P) \\
\text { amplitude }\end{array}$ & $\begin{array}{c}24,13(9,4) \\
5-40\end{array}$ & $\begin{array}{c}21,49(9,67) \\
7-40\end{array}$ & $\begin{array}{c}24,11(9,11) \\
8-39\end{array}$ & $\begin{array}{c}24,48(9,03) \\
5-40\end{array}$ & $\begin{array}{c}29,06(8,96) \\
7-38\end{array}$ & $\begin{array}{c}24,12(10,19) \\
6-40\end{array}$ \\
\hline $\begin{array}{l}\text { Gravidez múltipla } \\
\text { Não } \\
\text { Sim } \\
\text { Missings }\end{array}$ & $\begin{array}{c}426(92,81) \\
3(0,65) \\
30(6,54)\end{array}$ & $\begin{array}{c}112(100,00) \\
0(0,00) \\
0(0,00)\end{array}$ & $\begin{array}{c}72(94,74) \\
0(0,00) \\
4(5,26)\end{array}$ & $\begin{array}{c}121(89,63) \\
1(0,74) \\
13(9,63)\end{array}$ & $\begin{array}{c}12(70,59) \\
0(0,00) \\
5(29,41)\end{array}$ & $\begin{array}{c}30(88,24) \\
1(2,94) \\
3(8,82)\end{array}$ \\
\hline $\begin{array}{l}\text { Complicações obstétricas } \\
\text { Não } \\
\text { Sim }\end{array}$ & $\begin{array}{c}424(92,37) \\
35(7,63)\end{array}$ & $\begin{array}{c}108(96,43) \\
4(3,57)\end{array}$ & $\begin{array}{c}70(92,11) \\
6(7,89)\end{array}$ & $\begin{array}{c}125(92,59) \\
10(7,41)\end{array}$ & $\begin{array}{c}17(100,00) \\
0(0,00)\end{array}$ & $\begin{array}{c}32(94,12) \\
2(5,88)\end{array}$ \\
\hline
\end{tabular}

LVT = Lisboa e Vale do Tejo. NSE = Nível socioeconómico. IVG = Interrupção voluntária da gravidez.

${ }^{\dagger}$ Variável codificada de acordo com os procedimentos estabelecidos por Simões ${ }^{46}$. ${ }^{\ddagger}$ Variável codificada de acordo com a categorização do Instituto Nacional de Estatística. ${ }^{47}$ ${ }^{*} p<0,05 .{ }^{* *} p<0,01 .{ }^{* * *} p<0,001$. 
Tabela 1 - Caracterização da amostra em estudo: variáveis sociodemográficas e clínicas (final)

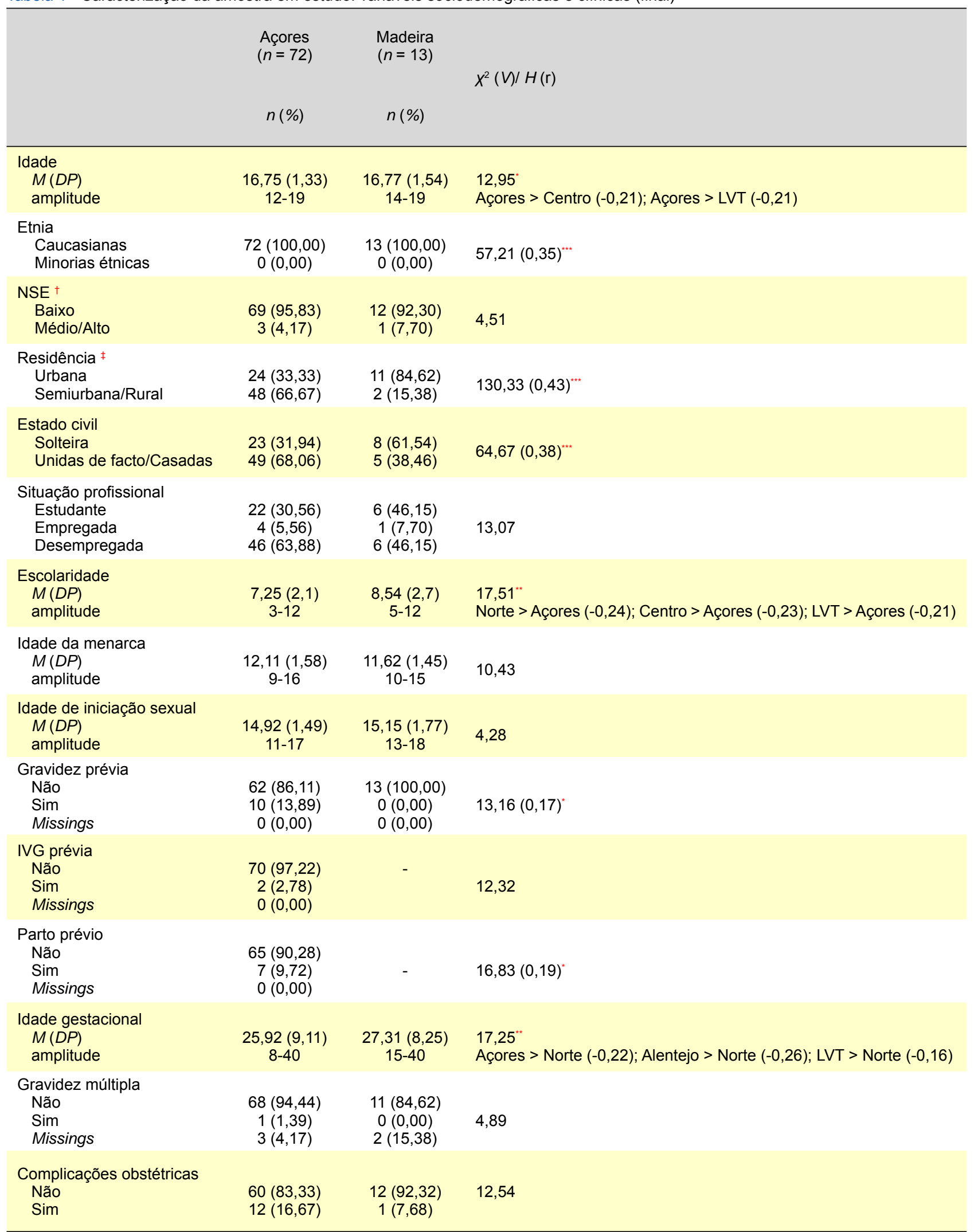

LVT = Lisboa e Vale do Tejo. NSE = Nível socioeconómico. IVG = Interrupção voluntária da gravidez.

Variável codificada de acordo com os procedimentos estabelecidos por Simões ${ }^{46}$. ${ }^{\ddagger}$ Variável codificada de acordo com a categorização do Instituto Nacional de Estatística. ${ }^{47}$ $p<0,05 .{ }^{* *} p<0,01 .{ }^{* * *} p<0,001$. 


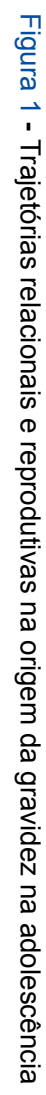
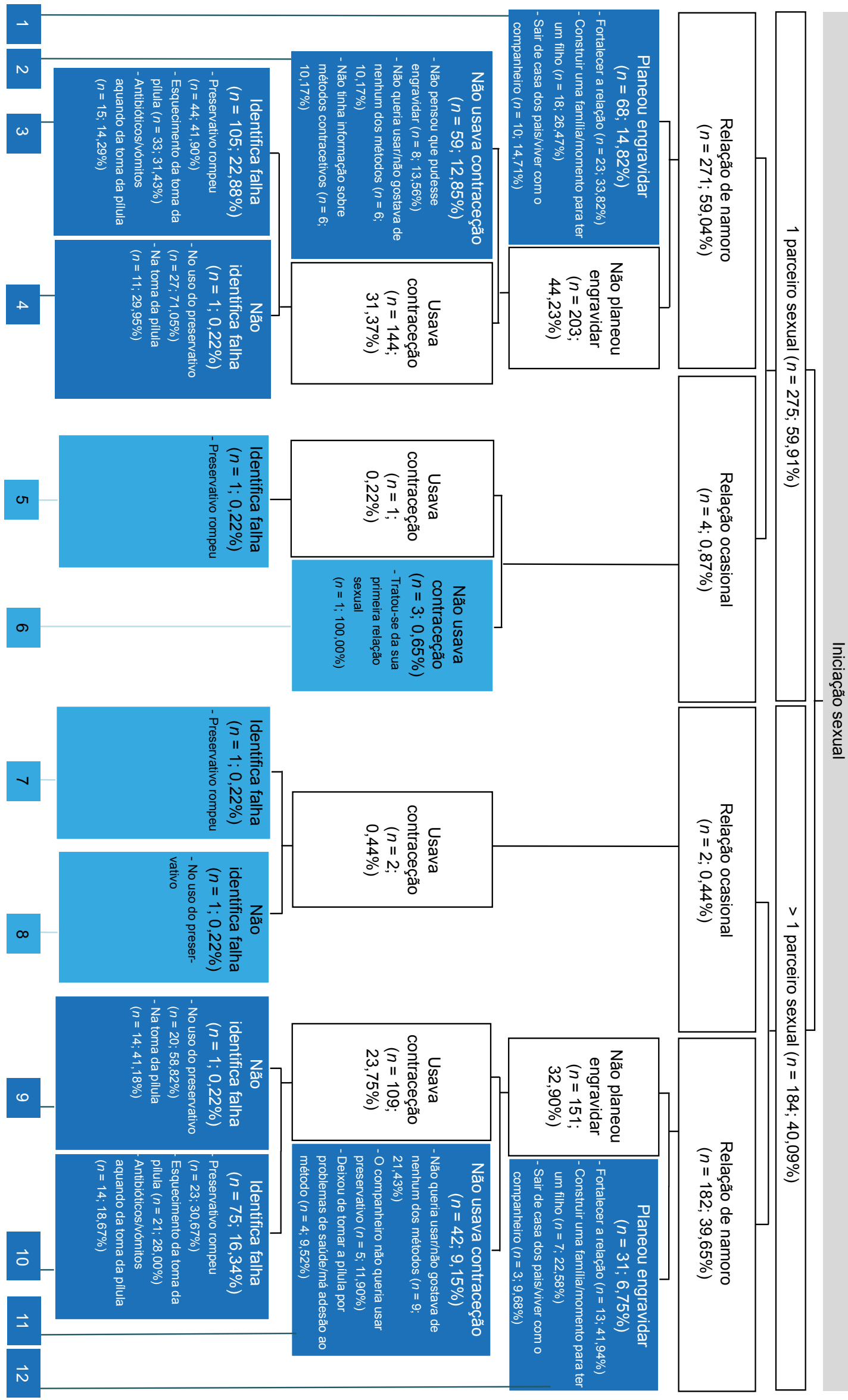
Tabela 2 - Características dos parceiros e da relação em que ocorreu a gravidez, por trajetória identificada (continua)

\begin{tabular}{|c|c|c|c|c|c|c|}
\hline & & Trajetórias & & & & \\
\hline & $\begin{array}{c}\text { Total } \\
(n=459)\end{array}$ & $\begin{array}{c}1 \\
(n=68)\end{array}$ & $\begin{array}{c}2 \\
(n=59)\end{array}$ & $\begin{array}{c}3 \\
(n=105)\end{array}$ & $\begin{array}{c}4 \\
(n=39)\end{array}$ & $\begin{array}{c}5 \\
(n=1)\end{array}$ \\
\hline & $n(\%)$ & $n(\%)$ & $n(\%)$ & $n(\%)$ & $n(\%)$ & $n(\%)$ \\
\hline \multicolumn{7}{|c|}{ Habilitações literárias do parceiro } \\
\hline Analfabeto & $1(0,21)$ & $0(0,00)$ & $0(0,00)$ & $1(0,95)$ & $0(0,00)$ & $0(0,00)$ \\
\hline Ensino Básico & $39(8,50)$ & $14(20,59)$ & $8(13,56)$ & $4(3,81)$ & $3(7,69)$ & $0(0,00)$ \\
\hline $2^{\circ}$ Ciclo & $105(22,88)$ & $19(27,94)$ & $14(23,73)$ & $21(20,00)$ & $7(17,95)$ & $0(0,00)$ \\
\hline $3^{\circ}$ Ciclo & $195(42,48)$ & $20(29,41)$ & $16(27,12)$ & $53(50,48)$ & $18(46,15)$ & $1(100,00)$ \\
\hline Ens. Secundário & $57(12,42)$ & $5(7,35)$ & $10(16,95)$ & $14(13,33)$ & $6(15,38)$ & $0(0,00)$ \\
\hline Ens. Superior & $2(0,44)$ & $0(0,00)$ & $1(1,69)$ & $1(0,95)$ & $0(0,00)$ & $0(0,00)$ \\
\hline Não sabe/Missing & $60(13,07)$ & $10(14,71)$ & $10(16,95)$ & $5(4,76)$ & $5(12,82)$ & $0(0,00)$ \\
\hline \multicolumn{7}{|c|}{ Situação profissional do parceiro } \\
\hline Estudante & $84(18,30)$ & $8(11,76)$ & $9(15,25)$ & $22(20,95)$ & $10(25,64)$ & $1(100,00)$ \\
\hline Empregado & $248(54,03)$ & $41(60,29)$ & $32(54,24)$ & $67(63,81)$ & $15(38,46)$ & $0(0,00)$ \\
\hline Desempregado & $97(21,13)$ & $17(25,00)$ & $13(22,03)$ & $13(12,38)$ & $10(25,64)$ & $0(0,00)$ \\
\hline Não sabe/Missing & $30(6,54)$ & $2(2,94)$ & $5(8,47)$ & $3(2,86)$ & $4(12,26)$ & $0(0,00)$ \\
\hline \multicolumn{7}{|c|}{ Diferença de idade do casal ${ }^{\dagger}$} \\
\hline$M(D P)$ & $4,25(3,53)$ & $4,81(3,91)$ & $4,00(4,17)$ & $3,74(2,78)$ & $3,76(3,81)$ & $-1,00$ \\
\hline amplitude & $-2-23$ & $-2-19$ & $-1-23$ & $0-16$ & $-1-20$ & - \\
\hline
\end{tabular}

Duração da relação *

$\begin{array}{lcccccc}M(D P) & 19,66(12,57) & 23,11(14,55) & 21,50(14,88) & 20,59(12,00) & 21,17(12,95) & - \\ \text { amplitude } & 2-84 & 4-72 & 2-67 & 5-84 & 4-60\end{array}$

1 = Adolescentes que engravidaram do seu primeiro parceiro sexual, numa relação de namoro e tendo planeado a gravidez; 2 = Adolescentes que engravidaram do seu primeiro parceiro sexual, numa relação de namoro, não tendo planeado a gravidez, mas não usando contraceção; 3 = Adolescentes que engravidaram do seu primeiro parceiro sexual, numa relação de namoro, utilizando contraceção e tendo identificado a falha contracetiva; 4 = Adolescentes que engravidaram do seu primeiro parceiro sexual, numa relação de namoro, utilizando contraceção mas não tendo identificado a falha contracetiva; 5 = Adolescentes que engravidaram do seu primeiro parceiro sexual, numa relação ocasional, usando contraceção e tendo identificado a falha contracetiva; 6 = Adolescentes que engravidaram do seu primeiro parceiro sexual, numa relação ocasional, usando contraceção mas não tendo identificado a falha contracetiva; 7 = Adolescentes que engravidaram após múltiplos parceiros sexuais, numa relação ocasional, usando contraceção e tendo identificado a falha contracetiva; 8 = Adolescentes que engravidaram após múltiplos parceiros sexuais, numa relação ocasional, usando contraceção mas não tendo identificado a falha contracetiva; 9 = Adolescentes que engravidaram após múltiplos parceiros sexuais, numa relação de namoro, não tendo planeado a gravidez, usando contraceção mas não tendo identificado a falha contracetiva; 10 = Adolescentes que engravidaram após múltiplos parceiros sexuais, numa relação de namoro, utilizando contraceção e tendo identificado a falha contracetiva; 11 = Adolescentes que engravidaram após múltiplos parceiros sexuais, numa relação de namoro, não tendo planeado a gravidez, mas não usando contraceção; 12 = Adolescentes que engravidaram após múltiplos parceiros sexuais, numa relação de namoro e tendo planeado a gravidez.

${ }^{\dagger}$ Medida em anos e calculada através da subtração da idade da adolescentes à idade do seu parceiro sexual. ${ }^{\ddagger}$ Medida em meses.

mais frequente incluiu adolescentes que engravidaram após múltiplos parceiros, numa relação de namoro e tendo planeado a gravidez (trajetória 12). As restantes trajetórias, com frequências apenas residuais, e as justificações mais frequentes no que se refere a cada acontecimento ou decisão em causa encontram-se igualmente representadas na Fig. 1.

Como é possível observar na Tabela 2, os parceiros 
Tabela 2 - Características dos parceiros e da relação em que ocorreu a gravidez, por trajetória identificada (final)

\begin{tabular}{|c|c|c|c|c|c|c|c|}
\hline & rajetórias & & & & & & \\
\hline & $\begin{array}{c}6 \\
(n=3)\end{array}$ & $\begin{array}{c}7 \\
(n=1)\end{array}$ & $\begin{array}{c}8 \\
(n=1)\end{array}$ & $\begin{array}{c}9 \\
(n=34)\end{array}$ & $\begin{array}{c}10 \\
(n=75)\end{array}$ & $\begin{array}{c}11 \\
(n=42)\end{array}$ & $\begin{array}{c}12 \\
(n=31)\end{array}$ \\
\hline & $n(\%)$ & $n(\%)$ & $n(\%)$ & $n(\%)$ & $n(\%)$ & $n(\%)$ & $n(\%)$ \\
\hline \multicolumn{8}{|c|}{ Habilitações literárias do parceiro } \\
\hline Analfabeto & $0(0,00)$ & $0(0,00)$ & $0(0,00)$ & $0(0,00)$ & $0(0,00)$ & $0(0,00)$ & $0(0,00)$ \\
\hline Ensino Básico & $0(0,00)$ & $0(0,00)$ & $0(0,00)$ & $1(2,94)$ & $1(1,33)$ & $3(7,14)$ & $5(16,12)$ \\
\hline $2^{\circ}$ Ciclo & $0(0,00)$ & $0(0,00)$ & $0(0,00)$ & $4(11,76)$ & $17(22,67)$ & $14(33,33)$ & $9(29,03)$ \\
\hline $3^{\circ}$ Ciclo & $0(0,00)$ & $0(0,00)$ & $1(100,00)$ & $16(47,06)$ & $37(49,33)$ & $16(38,10)$ & $11(35,48)$ \\
\hline Ens. Secundário & $0(0,00)$ & $0(0,00)$ & $0(0,00)$ & $6(17,65)$ & $10(13,33)$ & $4(9,52)$ & $2(6,45)$ \\
\hline Ens. Superior & $0(0,00)$ & $0(0,00)$ & $0(0,00)$ & $0(0,00)$ & $0(0,00)$ & $0(0,00)$ & $0(0,00)$ \\
\hline Não sabe/Missing & $3(100,00)$ & $1(100,00)$ & $0(0,00)$ & $7(20,59)$ & $10(13,33)$ & $7(16,67)$ & $4(12,90)$ \\
\hline \multicolumn{8}{|c|}{ Situação profissional do parceiro } \\
\hline Estudante & $1(33,33)$ & $0(0,00)$ & $1(100,00)$ & $10(29,41)$ & $11(14,67)$ & $7(16,67)$ & $4(12,90)$ \\
\hline Empregado & $1(33,33)$ & $1(100,00)$ & $0(0,00)$ & $15(44,12)$ & $36(48,00)$ & $21(50,00)$ & $19(61,29)$ \\
\hline Desempregado & $0(0,00)$ & $0(0,00)$ & $0(0,00)$ & $7(20,59)$ & $20(26,67)$ & $11(26,19)$ & $6(19,35)$ \\
\hline Não sabe/Missing & $1(33,33)$ & $0(0,00)$ & $0(0,00)$ & $2(5,88)$ & $8(10,67)$ & $3(7,14)$ & $2(6,45)$ \\
\hline \multicolumn{8}{|c|}{ Diferença de idade do casal ${ }^{\dagger}$} \\
\hline$M(D P)$ & $3,33(2,31)$ & 7,00 & 2,00 & $4,59(4,19)$ & $3,83(2,77)$ & $4,80(3,27)$ & $5,90(4,15)$ \\
\hline amplitude & $2-6$ & - & - & $0-18$ & $-1-13$ & $-1-13$ & $0-18$ \\
\hline \multicolumn{8}{|l|}{ Duração da relação ${ }^{\ddagger}$} \\
\hline$M(D P)$ & - & - & - & $13,61(8,07)$ & $17,56(9,84)$ & $15,53(9,46)$ & $20,48(14,73)$ \\
\hline amplitude & & & & $5-36$ & $3-48$ & $2-36$ & $2-60$ \\
\hline
\end{tabular}

1 = Adolescentes que engravidaram do seu primeiro parceiro sexual, numa relação de namoro e tendo planeado a gravidez; 2 = Adolescentes que engravidaram do seu primeiro parceiro sexual, numa relação de namoro, não tendo planeado a gravidez, mas não usando contraceção; 3 = Adolescentes que engravidaram do seu primeiro parceiro sexual, numa relação de namoro, utilizando contraceção e tendo identificado a falha contracetiva; 4 = Adolescentes que engravidaram do seu primeiro parceiro sexual, numa relação de namoro, utilizando contraceção mas não tendo identificado a falha contracetiva; 5 = Adolescentes que engravidaram do seu primeiro parceiro sexual, numa relação ocasional, usando contraceção e tendo identificado a falha contracetiva; 6 = Adolescentes que engravidaram do seu primeiro parceiro sexual, numa relação ocasional, usando contraceção mas não tendo identificado a falha contracetiva; 7 = Adolescentes que engravidaram após múltiplos parceiros sexuais, numa relação ocasional, usando contraceção e tendo identificado a falha contracetiva; 8 = Adolescentes que engravidaram após múltiplos parceiros sexuais, numa relação ocasional, usando contraceção mas não tendo identificado a falha contracetiva; 9 = Adolescentes que engravidaram após múltiplos parceiros sexuais, numa relação de namoro, não tendo planeado a gravidez, usando contraceção mas não tendo identificado a falha contracetiva; 10 = Adolescentes que engravidaram após múltiplos parceiros sexuais, numa relação de namoro, utilizando contraceção e tendo identificado a falha contracetiva; 11 = Adolescentes que engravidaram após múltiplos parceiros sexuais, numa relação de namoro, não tendo planeado a gravidez, mas não usando contraceção; 12 = Adolescentes que engravidaram após múltiplos parceiros sexuais, numa relação de namoro e tendo planeado a gravidez.

Medida em anos e calculada através da subtração da idade da adolescentes à idade do seu parceiro sexual. ${ }^{\ddagger}$ Medida em meses.

das adolescentes que engravidaram de forma planeada (trajetórias 1 e 12) foram aqueles que de forma mais frequente detinham habilitações literárias correspondentes ao ensino básico e se encontravam fora do sistema de ensino.
Verificámos ainda uma maior diferença de idades entre o casal nestas trajetórias do que nas restantes. Foi nas trajetórias em que as adolescentes engravidaram no contexto de utilização de contraceção sem que tivessem identificado 
a falha contracetiva (trajetórias 4 e 9) que detetámos com maior frequência parceiros integrados no sistema de ensino. Verificámos ainda que as relações de namoro das jovens que engravidaram do seu primeiro parceiro (trajetórias 1, 2, 3 e 4) se caracterizavam por menores diferenças de idade entre o casal e eram tendencialmente mais duradouras e do que as relações de namoro das jovens que engravidaram após múltiplos parceiros (trajetórias 9, 10, 11 e 12). No entanto, não foram detetadas diferenças significativas nestas variáveis quando comparadas as trajetórias equivalentes entre os dois grupos.

Por fim, detetámos oscilações quanto às trajetórias mais frequentes em cada região (Tabela 3). No Norte, em LVT e no Algarve, as jovens engravidaram de forma mais frequente do seu primeiro parceiro sexual, numa relação de namoro, não tendo planeado a gravidez, usando contraceção e tendo identificado a falha contracetiva (trajetória 3). As adolescentes do Centro e dos Açores engravidaram de forma mais frequente não só no contexto dessa mesma trajetória, como ainda do seu primeiro parceiro, numa relação de namoro, sem planeamento da gravidez, e não usando contraceção (trajetória 2) ou tendo planeado a gravidez (trajetória 1), respetivamente. Na região do Alentejo as adolescentes engravidaram de forma mais frequente do seu primeiro parceiro, numa relação de namoro e tendo planeado a gravidez (trajetória 1). Na Madeira verificouse a existência de quatro trajetórias com igual frequência, três das quais menos prevalentes nas restantes regiões: adolescentes que engravidaram do seu primeiro parceiro, numa relação de namoro, não tendo planeado a gravidez, usando contraceção e não tendo identificado a falha contracetiva (trajetória 4) e adolescentes que engravidaram após múltiplos parceiros, numa relação de namoro, não tendo planeado a gravidez, usando contraceção e tendo identificado a falha contracetiva (trajetória 10) ou não usando contraceção (trajetória 11).

\section{DISCUSSÃO}

Pretendeu-se caracterizar as trajetórias relacionais e reprodutivas conducentes à gravidez na adolescência em Portugal, explorando a existência de especificidades regionais neste processo. Foram identificadas doze trajetórias; as mais frequentes no Norte, Centro, LVT, Algarve, Açores e Madeira incluíram adolescentes que engravidaram do seu primeiro parceiro sexual, numa relação de namoro, usando contraceção e tendo identificado a falha contracetiva. Em determinadas regiões verificou-se, no entanto, uma prevalência igualmente elevada de trajetórias que incluíram o planeamento da gravidez (Alentejo/Açores), a ausência de contraceção (Centro/Madeira) ou a sua utilização ineficaz sem identificação da falha contracetiva (Madeira). Sobressaíram ainda particularidades ao nível dos contextos relacionais inerentes à ocorrência destas gravidezes, que impõem cuidados adicionais na generalização dos resultados

Tabela 3 - Distribuição das trajetórias relacionais e reprodutivas, por região

\begin{tabular}{cccccccc}
\hline & $\begin{array}{c}\text { Norte } \\
(n=112)\end{array}$ & $\begin{array}{c}\text { Centro } \\
(n=76)\end{array}$ & $\begin{array}{c}\text { LVT } \\
(n=135)\end{array}$ & $\begin{array}{c}\text { Alentejo } \\
(n=17)\end{array}$ & $\begin{array}{c}\text { Algarve } \\
(n=34)\end{array}$ & $\begin{array}{c}\text { Açores } \\
(n=72)\end{array}$ & $\begin{array}{c}\text { Madeira } \\
(n=13)\end{array}$ \\
\hline Trajetória & $n(\%)$ & $n(\%)$ & $n(\%)$ & $n(\%)$ & $n(\%)$ & $n(\%)$ & $n(\%)$ \\
1 & $11(9,82)$ & $11(14,47)$ & $19(14,07)$ & $5(29,41)$ & $6(17,65)$ & $15(20,83)$ & $1(7,69)$ \\
2 & $5(4,46)$ & $15(19,73)$ & $15(11,11)$ & $1(5,88)$ & $8(23,53)$ & $14(19,44)$ & $1(7,69)$ \\
3 & $39(34,82)$ & $15(19,73)$ & $23(17,04)$ & $1(5,88)$ & $10(29,41)$ & $15(20,83)$ & $2(15,38)$ \\
4 & $6(5,36)$ & $4(5,26)$ & $20(14,81)$ & $0(0,00)$ & $3(8,82)$ & $4(5,56)$ & $2(15,38)$ \\
5 & $0(0,00)$ & $1(1,32)$ & $0(0,00)$ & $0(0,00)$ & $0(0,00)$ & $0(0,00)$ & $0(0,00)$ \\
6 & $0(0,00)$ & $0(0,00)$ & $1(0,74)$ & $0(0,00)$ & $0(0,00)$ & $1(1,39)$ & $1(7,69)$ \\
7 & $0(0,00)$ & $1(1,32)$ & $0(0,00)$ & $0(0,00)$ & $0(0,00)$ & $0(0,00)$ & $0(0,00)$ \\
8 & $0(0,00)$ & $0(0,00)$ & $1(0,74)$ & $0(0,00)$ & $0(0,00)$ & $0(0,00)$ & $0(0,00)$ \\
9 & $9(8,04)$ & $5(6,58)$ & $13(9,63)$ & $4(23,53)$ & $1(2,94)$ & $1(1,39)$ & $1(7,69)$ \\
10 & $31(27,68)$ & $8(10,53)$ & $19(14,07)$ & $3(17,65)$ & $3(8,82)$ & $9(12,50)$ & $2(15,38)$ \\
11 & $5(4,46)$ & $11(14,47)$ & $15(11,11)$ & $2(11,77)$ & $2(5,89)$ & $5(6,94)$ & $2(15,38)$ \\
12 & $6(5,36)$ & $5(6,58)$ & $9(6,67)$ & $1(5,88)$ & $1(2,94)$ & $8(11,11)$ & $1(7,69)$ \\
\hline
\end{tabular}

LVT = Lisboa e Vale do Tejo.

1 = Adolescentes que engravidaram do seu primeiro parceiro sexual, numa relação de namoro e tendo planeado a gravidez; $2=$ Adolescentes que engravidaram do seu primeiro parceiro sexual, numa relação de namoro, não tendo planeado a gravidez, mas não usando contraceção; 3 = Adolescentes que engravidaram do seu primeiro parceiro sexual, numa relação de namoro, utilizando contraceção e tendo identificado a falha contracetiva; 4 = Adolescentes que engravidaram do seu primeiro parceiro sexual, numa relação de namoro, utilizando contraceção mas não tendo identificado a falha contracetiva; $5=$ Adolescentes que engravidaram do seu primeiro parceiro sexual, numa relação ocasional, usando contraceção e tendo identificado a falha contracetiva; 6 = Adolescentes que engravidaram do seu primeiro parceiro sexual, numa relação ocasional, usando contraceção mas não tendo identificado a falha contracetiva; 7 = Adolescentes que engravidaram após múltiplos parceiros sexuais, numa relação ocasional, usando contraceção e tendo identificado a falha contracetiva; 8 = Adolescentes que engravidaram após múltiplos parceiros sexuais, numa relação ocasional, usando contraceção mas não tendo identificado a falha contracetiva; 9 = Adolescentes que engravidaram após múltiplos parceiros sexuais, numa relação de namoro, não tendo planeado a gravidez, usando contraceção mas não tendo identificado a falha contracetiva; 10 = Adolescentes que engravidaram após múltiplos parceiros sexuais, numa relação de namoro, utilizando contraceção e tendo identificado a falha contracetiva; $11=$ Adolescentes que engravidaram após múltiplos parceiros sexuais, numa relação de namoro, não tendo planeado a gravidez, mas não usando contraceção; 12 = Adolescentes que engravidaram após múltiplos parceiros sexuais, numa relação de namoro e tendo planeado a gravidez. 
internacionais para a realidade portuguesa.

Os nossos resultados foram congruentes com a literatura que sugere a importância das falhas contracetivas na ocorrência da gravidez adolescente. ${ }^{22-24,33-35}$ As falhas identificadas disseram maioritariamente respeito a situações detetáveis - como o rompimento do preservativo ou o esquecimento da toma da pílula -, o que, no entanto, parece não ter levado as adolescentes a comportamentos alternativos, como o recurso à utilização de contraceção de emergência. Apesar de não conhecermos as justificações das jovens para este facto, consideramos possível hipotetizar que este se possa ter devido a uma perceção inadequada do risco de gravide $z^{48}$ ou à ausência de informação e/ou competências que thes permitissem mobilizar adequadamente esta estratégia. Segundo diversos estudos, o conhecimento das adolescentes sobre a ação da contraceção de emergência, as situações nas quais deve ser usada e a forma como podem aceder-lhe é reduzido. ${ }^{48-51}$ Carvalho refere, no mesmo sentido, que quando questionadas acerca dos métodos contracetivos capazes de evitar uma gravidez apenas 1,4\% a $3,6 \%$ das grávidas adolescentes da sua amostra mencionaram a contraceção de emergência; esta percentagem foi nula no Sul do país. ${ }^{30}$ Acresce que a identificação da falha contracetiva ocorreu em relações de namoro caracterizadas por menores diferenças de idades com o parceiro, o que pode ser indicativo da maior inexperiência do casal, e não apenas da adolescente, a estes níveis. Segundo Castro e Rodrigues, ${ }^{52}$ entre adolescentes de idades semelhantes, os rapazes detêm um menor conhecimento efetivo sobre contraceção. Também perceções negativas sobre os efeitos secundários, ${ }^{50}$ custo $^{48}$ e disponibilização confidencial da contraceção de emergência poderão ter constituído barreiras à sua utilização. ${ }^{48,50}$

Apesar da necessidade de investigações futuras que clarifiquem estas hipóteses, os resultados disponíveis indicam que a educação das adolescentes e dos seus parceiros sobre possíveis falhas na utilização de métodos contracetivos, o risco de gravidez a elas inerente e a ação da contraceção de emergência, assim como a identificação e remoção das barreiras percebidas no acesso à mesma, deverão ser áreas a priorizar nas políticas de saúde do nosso país com vista a uma redução efetiva da gravidez precoce. Para além da introdução destes temas nos currículos escolares, maximizada pela aplicação da Portaria $n^{\circ}$ 196-A/2010 de 9 de abril, que regulamenta a Lei 60/2009 de 6 de agosto, será particularmente relevante a ação eficaz dos serviços de saúde. Para além das Consultas de Planeamento Familiar nos Cuidados de Saúde Primários e Hospitalares e dos Centros de Atendimento Jovem, as consultas de Medicina Geral e Familiar, nomeadamente pelo contacto mais próximo e regular que proporcionam com a população, podem constituir importantes oportunidades para ações desse âmbito. ${ }^{51}$

Os nossos resultados reforçam, igualmente, a importância atribuída pela literatura à decisão de engravidar. ${ }^{22,27-29}$ A terceira trajetória nacionalmente mais frequente incluiu jovens que engravidaram numa relação de namoro com o seu primeiro parceiro sexual e que planearam a gravidez. Esta trajetória, dominante no Alentejo e nos Açores, parece ser mais frequente entre adolescentes mais velhas, de meios semiurbanos/rurais e menos escolarizadas e associar-se a situações de casamento/união de facto e partos prévios. Estes resultados sugerem que a recorrência da gravidez na adolescência pode encontrar-se associada a projetos de vida voltados para a conjugalidade e maternidade, nomeadamente em regiões habitualmente caracterizadas por um menor leque de oportunidades de desenvolvimento/ crescimento pessoal e de projetos de vida escolarizados/ profissionalizantes. ${ }^{53}$ Neste sentido, a avaliação das representações e expectativas das jovens acerca do seu percurso académico/profissional, da sua realização pessoal e da relação com o parceiro e a promoção de projetos de vida alternativos à maternidade podem ser estratégias de particular relevância nestas regiões.

O envolvimento dos parceiros das adolescentes de maior risco na prevenção da gravidez parece igualmente útil no âmbito desta trajetória. Os nossos resultados são congruentes com estudos prévios, ao sugerirem que, quando enquadrada numa relação de namoro, a gravidez adolescente ocorre em relações duradouras ${ }^{37}$ e com homens mais velhos, ${ }^{4,22,30,38}$ com baixas habilitações literárias e excluídos do sistema de ensino, ${ }^{4,30,38-40}$ tendo sido estes resultados particularmente expressivos quando a gravidez foi planeada. ${ }^{31}$ Diversos autores consideram que estas características determinam em larga medida a ineficácia de alguns programas de prevenção. Estes são habitualmente pouco integradores da população masculina descrita, quer por ocorrerem em contexto escolar, quer por ocorrerem em contextos de saúde e/ou comunitários sendo dirigidos apenas a adolescentes. ${ }^{54}$ Os nossos resultados apontam, então, para a necessidade de repensar as políticas de educação e de saúde de forma a incluir a população masculina de maior risco nas ações delineadas e a promover uma sexualidade segura na comunidade, entre pares e fora do contexto escolar. As consultas de planeamento familiar podem constituir-se, a este nível, como contextos privilegiados para envolver os parceiros de maior risco na prevenção da gravidez. Seria desejável, porém, que investigações futuras esclarecessem o impacto destes parceiros nas decisões reprodutivas das jovens. Alguns autores referem que este pode dever-se ao desejo que esses parceiros têm, ou que as adolescentes Ihes atribuem, de serem pais naquele momento das suas vidas e ao elevado poder que assumem nas relações de namoro. ${ }^{55,56}$

Por seu lado, as trajetórias associadas à ausência de contraceção estiveram particularmente envolvidas na ocorrência de gravidez no Centro e na Madeira. Tal facto espelha a necessidade de não desinvestir das políticas de saúde que visam a promoção da utilização de contraceção, sendo, no entanto, necessário avaliar as razões pelas quais os resultados alcançados nestas regiões não são totalmente satisfatórios. De acordo com os nossos dados, as jovens do Centro parecem necessitar de mais informação sobre métodos contracetivos e respetiva acessibilidade, e 
de um maior suporte na ponderação do risco envolvido em relações desprotegidas, enquanto as adolescentes da Madeira parecem poder beneficiar da promoção de competências de negociação da contraceção de barreira com os seus parceiros e de um aconselhamento contracetivo especialmente atento à sua má adesão a métodos contracetivos hormonais, como a pílula. Em ambas as situações, parece ser importante desmistificar desvantagens percebidas na sua utilização, esclarecer os benefícios não contracetivos de que poderiam advir da mesma e envolver ativamente as adolescentes na escolha do método que melhor se adapte à sua situação. ${ }^{34}$

Na região da Madeira as trajetórias associadas à ausência de identificação da falha contracetiva estiveram igualmente entre as que de forma mais frequente conduziram à gravidez. Uma dessas trajetórias revelou-se ainda a segunda mais frequente em LVT, região onde a gravidez na adolescência é particularmente prevalente. ${ }^{13} \mathrm{~A}$ promoção e o treino de competências ao nível da identificação das possíveis falhas contracetivas parecem, assim, iniciativas a priorizar nestas regiões. A par da prevenção em contexto de saúde e/ou comunitário, programas de âmbito escolar poderão desempenhar um papel mais revelante nestas situações do que nas anteriormente discutidas, uma vez que nestas trajetórias foi detetado um maior número de parceiros incluídos no sistema de ensino.

Por fim, e contrariamente à literatura internacional, ${ }^{28,36,39}$ apenas uma minoria residual das adolescentes engravidou numa relação ocasional e apenas na Madeira as trajetórias que incluíram o envolvimento com múltiplos parceiros estiveram entre as mais frequentes. Acresce que a única discrepância encontrada entre as jovens que reportaram um e múltiplos parceiros prendeu-se com o planeamento da gravidez, mais frequente entre as primeiras. As restantes trajetórias revelaram-se equivalentes. A integração deste conhecimento na prática de educadores e profissionais de saúde poderá aumentar a adequabilidade da sua atuação às necessidades das jovens portuguesas, contribuindo para uma maior adesão às medidas implementadas. No entanto, a elevada amplitude detetada nas diferenças de idades entre o casal levanta importantes questões, nomeadamente legais, ao nível destes relacionamentos. $O$ investimento na compreensão das circunstâncias em que os mesmos se estabelecem e perduram parece-nos, assim, de elevada pertinência.

Algumas limitações deste estudo devem ser consideradas: a sua metodologia transversal exige prudência na generalização dos resultados, pois apesar da sequência temporal dos acontecimentos ter sido assegurada no estudo das trajetórias, investigações futuras deverão privilegiar uma metodologia longitudinal; o caráter retrospetivo das respostas pode ter aumentado a presença de enviesamentos típicos desse tipo de avaliação ${ }^{57}$ e a natureza sensível das questões incrementado a probabilidade de respostas socialmente desejáveis. ${ }^{58,59}$ Avaliar simultaneamente os parceiros das jovens, explorando incongruências entre as fontes, poderá ser uma estratégia válida em investigações futuras.
Não obstante, os nossos resultados constituem conhecimento específico sobre os contextos relacionais e reprodutivos em que a gravidez na adolescência ocorre, tendo importantes implicações. A multiplicidade de trajetórias identificadas e a sua variação regional refletem a necessidade de evitar visões globais e/ou estereotipadas das adolescentes que engravidam e, em alternativa, investir em políticas de saúde simultaneamente abrangentes e diversificadas, que atendam às necessidades particulares das jovens de cada região. Uma vez que proporcionar um aconselhamento contracetivo eficaz exige a compreensão das necessidades da população específica a que este se dirige,$^{34}$ os nossos resultados poderão ser igualmente relevantes ao nível da atuação dos profissionais que prestam cuidados de saúde à população adolescente. De facto, as consultas de planeamento familiar são locais privilegiados para uma educação sexual adequada e antecipada ${ }^{60}$. Na adolescência, em particular, a população de maior risco encontra-se habitualmente fora do sistema de ensino ou retida em anos escolares não normativos, ${ }^{1,30}$ o que restringe o seu acesso a uma educação sexual formal adequada ao seu nível de desenvolvimento em contexto escolar, pelo que a ação dos profissionais de saúde poderá ser determinante.

\section{CONCLUSÃO}

Os nossos resultados salientam a importância de atender à diversidade regional portuguesa ao nível do planeamento do(a): 1) difusão de informação sobre métodos contracetivos, 2) desenvolvimento de projetos de vida alternativos à maternidade, 3) promoção da utilização de contraceção, 4) educação ao nível da identificação de possíveis falhas contracetivas e do risco de gravidez a elas inerente e 5) promoção e treino de competências para lidar com essas falhas. O conhecimento que deles emerge fornece-nos, assim, importantes orientações para a prevenção nacional da ocorrência de gravidez na adolescência, fundamentando a importância de investir na prevenção das decisões e dos comportamentos de risco de acordo com as especificidades regionais identificadas.

\section{CONFLITOS DE INTERESSE}

Os autores não têm conflitos de interesse a declarar.

\section{FONTES DE FINANCIAMENTO}

Subsídios e bolsas que contribuíram para a realização do trabalho: estudo integrado no projeto de investigação Gravidez na adolescência em Portugal: Etiologia, decisão reprodutiva e adaptação, da responsabilidade da Linha de Investigação Relações, Desenvolvimento \& Saúde do Instituto de Psicologia Cognitiva, Desenvolvimento Vocacional e Social da Universidade de Coimbra (Unidade I\&D, PEst-OE/PSI/UI0192/2011). Durante a sua execução, os três primeiros autores foram financiados pela Fundação para a Ciência e Tecnologia através de Bolsas Individuais de Doutoramento (SFRH/BD/63949/2009, SFRH/BD/89435/2012 e SFRH/BD/3168/2000, respetivamente). 


\section{REFERÊNCIAS}

1. Araújo Pedrosa A, Pires R, Carvalho P, Canavarro MC, Dattilio FM. Ecological contexts in adolescent pregnancy: the role of individual, sociodemographic, familial and relational variables in understanding risk of occurrence and adjustment patterns. Contemp Fam Ther. 2011;33:107-27.

2. Pires R, Araújo Pedrosa A, Canavarro MC. Examining the links between perceived pregnancy impact, depression, and quality of life during adolescent pregnancy: the buffering role of social support. Matern Child Health J. 2014;18:789-800.

3. da Silva MO. A gravidez na adolescência: relevância clínica da intervenção pré-natal . Lisboa: Universidade de Lisboa; 1992.

4. Araújo Pedrosa A. Gravidez e transição para a maternidade na adolescência: determinantes individuais e psicossociais da ocorrência de gravidez e da adaptação. Estudo com adolescentes da Região Autónoma dos Açores. Coimbra: Universidade de Coimbra; 2009.

5. Canavarro MC, Pereira Al. Gravidez e maternidade da adolescência: perspectivas teóricas. In: Canavarro MC, editor. Psicologia da gravidez e maternidade. Coimbra: Quarteto; 2001. p. 323-57.

6. Derme M, Leoncini E, Vetrano G, Carlomagno L, Aleandri V. Obstetric and perinatal outcomes of teenage pregnant women: a retrospective study. Epidemiol Biostatist Publ Health. 2013;10:1-8.

7. Kashan AS, Baker PN, Kenny LC. Preterm birth and reduced birth weight in first and second teenage pregnancies: a register-based cohort study. BMC Pregnancy Childbirth. 2010;10:36-44

8. Leppälahti S, Gissler M, Mentula M, Heikinheimo O. Is teenage pregnancy an obstetric risk in welfare society? A population-based study in Finland, from 2006 to 2011. BMJ Open. 2013;3:1-10.

9. Santos RS. Gravidez em mães adolescentes: estudo no distrito de Beja 1986-1991. Acta Med Port. 1997;10:681-8.

10. Figueiredo $B$, Pacheco A, Costa R. Depression during pregnancy and the postpartum period in adolescents and adult Portuguese mothers. Arch Womens Ment Health. 2007;10:103-9.

11. Silva MO da, Albrecht J, Olsen J, Karro H, Temmerman M, Gissler M, et al. The reproductive health report: the state of sexual and reproductive health within the European Union. Eur J Contracept Reprod Health Care. 2011:16:S1-70.

12. United Nations Population Fund. The state of world population 2012: by choice, not by chance - family planning, human rights and development. New York: UNPF; 2012.

13. PORDATA. Nados-vivos de mães residentes em Portugal: total e por grupo etário da mãe - municípios. [consultado 2013 Set 09]. Disponível em: http://www.pordata.pt/Municipios/Nados+vivos+de+maes+resident es+em+Portugal+total+e+por+grupo+etario+da+mae-104

14. Direção-Geral da Saúde. Relatório dos registos das interrupções da gravidez ao abrigo da lei 16/2007, de 17 de abril: dados referentes ao período de janeiro a dezembro de 2009. Lisboa: DGS; 2010.

15. Direção-Geral da Saúde. Relatório dos registos das interrupções da gravidez ao abrigo da lei 16/2007, de 17 de abril: dados referentes ao período de janeiro a dezembro de 2010. Lisboa: DGS; 2011.

16. Direção-Geral da Saúde. Relatório dos registos das interrupções da gravidez ao abrigo da lei 16/2007, de 17 de abril: dados referentes ao período de janeiro a dezembro de 2011 - edição revista. Lisboa: DGS; 2013.

17. Direção-Geral da Saúde. Relatório dos registos das interrupções da gravidez ao abrigo da lei 16/2007, de 17 de abril: dados referentes ao período de janeiro a dezembro de 2012. Lisboa:DGS; 2013.

18. Rafaelli M, Crockett LJ. Sexual risk taking in adolescence: the role of self-regulation and attraction to risk. Dev Psychol. 2003;39:1036-46.

19. Coley RL, Chase-Lansdale L. Adolescent pregnancy and parenthood: recent evidence and future directions. Am Psychol. 1998:53:152-66.

20. Hawes ZC, Wellings K, Stephenson J. First sexual intercourse in the United Kingdom: a review of the literature. J Sex Res. 2010;47:137-52.

21. Pires R, Araújo Pedrosa A, Carvalho P, Pereira J, Canavarro MC. Why do adolescents keep getting pregnant: is this due to intention to get pregnant, non-use of contraceptives, contraceptive failure or incorrect use? Int J Behav Med. 2012;19:132-3.

22. Pires R, Pereira J, Araújo Pedrosa A, Canavarro MC. Maternidade adolescente: escolha, aceitação ou resignação? Psicol Saúde Doenças. 2013;14:339-47.

23. Abma JC, Chandra A, Mosher WD, Peterson LS, Piccinino LJ. Fertility, family planning, and women's health: new data from the 1995 National Survey of Family Growth. Vital Health Stat. 1997;23:1-114.

24. Jones RK, Darroch JE, Henshaw SK. Contraceptive use among U.S. women having abortions in 2000-2001. Perspect Sex Reprod Health. 2002;34:294-303.
25. Figueiredo B, Pacheco A, Magarinho R. Grávidas adolescentes e adultas: diferentes circunstâncias de risco? Acta Med Port. 2005;18:97-105.

26. Tavares M, Barros H. Gravidez não planeada em Portugal. Acta Med Port. 1997;10:351-6.

27. Abma JC, Martinez GM, Mosher WD, Dawson BS. Teenagers in the United States: sexual activity, contraceptive use, and childbearing 2002. Vital Health Stat. 2004;23:1-48.

28. Davies SL, DiClemente RJ, Wingood GM, Person SD, Dix ES Harrington K, et al. Predictors of inconsistent contraceptive use among adolescent girls: findings from a prospective study. J Adolesc Health. 2006;39:43-9

29. Sheeder J, Tocce K, Stevens-Simon C. Reasons for ineffective contraceptive use antedating adolescent pregnancies: part 2: a proxy for childbearing intentions. Matern Child Health J. 2009;13:306-17.

30. Carvalho P. Fatores de influência individuais, psicossociais e relacionais para a ocorrência de gravidez na adolescência em Portugal Continental. Covilhã: Universidade da Beira Interior; 2012

31. Agurcia CA, Tickert VI, Bereson AB, Volk RJ, Wiemann CM. The behavioral risks and life circumstances of adolescent mothers involved with older adult partners. Arch Pediatr Adolesc Med. 2001;155:822-30.

32. Instituto Nacional de Estatística. $4^{\circ}$ Inquérito Nacional de Saúde 2005/2006. Lisboa: Instituto Nacional de Estatística; 2007.

33. Klerman LV. The intendedness of pregnancy: a concept in transition Matern Child Health J. 2000;4:155-62.

34. Sampaio MG, Chaves I, Dias A. Contracepção hormonal oral. Acta Med Port. 2000;13:231-6.

35. Tripp J, Viner R. Sexual health, contraception, and teenage pregnancy. BMJ. 2005;330:590-3

36. Ford K, Sohn W, Lepkowski J. Characteristics of adolescents' sexua partners and their association with use of condoms and other contraceptive methods. Fam Plann Perspect. 2001;33:100-32.

37. Manning WD, Flanigan CM, Giordano PC, Longmore MA. Relationship dynamics and consistency of condom. Perspect Sex Reprod Health. 2009;41:181-90.

38. Sheeder J, Tocce K, Stevens-Simon C. Reasons for ineffective contraceptive use antedating adolescent pregnancies: part 1: an indicator of gaps in family planning services. Matern Child Health J. 2009;13:295305 .

39. Lindberg LD, Sonestein FL, Ku L, Martinez G. Age differences between minors who give birth and their adult partners. Fam Plann Perspect. 1997;29:61-6.

40. Taylor DJ, Chavez GF, Adams EJ, Chabra A, Shah R. Demographic characteristics in adult paternity for first births to adolescents under 15 years of age. J Adolesc Health. 1999;24:251-8.

41. William M. Adolescent males' orientation toward paternity and contraception. Fam Plann Perspect. 1993;25:22-31.

42. World Health Organization. Pregnancy and abortion in adolescence. Report of a WHO meeting World Health Organ Tech Rep Ser. 1975;(583):127.

43. Araújo Pedrosa A, Canavarro MC, Pereira M. Entrevista de avaliação clínica para as utentes da unidade de intervenção psicológica da Maternidade Doutor Daniel de Matos, HUC. Coimbra: Universidade de Coimbra; 2003.

44. Cohen J. A power primer. Psychol Bull. 1992;112:155-9.

45. Field A. Discovering statistics using SPSS. $3^{\text {nd }}$ ed. London: Sage Publications; 2009.

46. Simões MR. Investigações no âmbito da aferição nacional do teste das Matrizes Progressivas de Raven. Coimbra: Universidade de Coimbra; 1994.

47. Instituto Nacional de Estatística. Tipologia de áreas urbanas (TIPAU) Lisboa: INE; 2009.

48. Johnson R, Nshom M, Nye AM, Cohall AT. There's always plan B: adolescent knowledge, attitudes and intention to use emergency contraception. Contraception. 2010;81:128-32.

49. Lindberg CE. Emergency contraception for prevention of adolescent pregnancy. MCN Am J Matern Child Nurs. 2003;28:199-204.

50. Mollen CJ, Barg FK, Hayes KL, Gotcsik M, Blades NM, Schwarz DF Assessing attitudes about emergency contracetion among urban, minor, adolescent girls: an in-depth interview study. Pediatrics. 2008;122:e329401

51. Nunes TM. Conhecimento e utilização da contracepção de emergência em alunas do ensino secundário em Guimarães. Rev Port Clin Geral. 2005;21:247-56.

52. Castro JF, Rodrigues VM. Conhecimentos e atitudes dos jovens face 
à contraceção de emergência. Rev Esc Enferm USP. 2009;43:889-94.

53. Instituto Nacional de Estatística. Índice sintético de desenvolvimento regional. Lisboa: INE; 2009.

54. Males M, Chew SY. The ages of fathers in California adolescent births, 1993. Am J Public Health. 1996;86:565-8.

55. Osorio A, López-del Burgo C, Carlos S, Ruiz-Canela M, Delgado M, Irala J. First sexual intercourse and subsequent regret in three developing countries. J Adolesc Health. 2012;50:271-8.

56. Wang R-H, Chiou C-J. Relative contribution of intrapersonal and partner factors to contraceptive behavior among Taiwanese female adolescents. J Nurs Scholarsh. 2008;40:131-6.

57. Logan C, Holcombe E, Manlove J, Ryan S. The consequences of unin- tended childbearing: a white paper. Washington: Child Trends, and the National Campaign to Prevent Teen and Unplanned Pregnancy; 2007.

58. Palen L-A, Smith E, Caldwell LL, Flisher AJ, Wegner L, Vergnani T. Inconsistent reports of sexual intercourse among South African high school students. J Adolesc Health. 2008;42:221-7.

59. Rose E, DiClemente RJ, Wingood GM, Sales JM, Latham TP, Crosby RA, et al. The validity of teens' and young adults' self-reported condom use. Arch Pediatr Adolesc Med. 2009;163:61-4

60. Nobre S, Tomé MT. As citologias na promoção da saúde sexual das adolescentes utentes do Centro de Atendimento a Jovens de Coimbra. Acta Med Port. 2011;24:413-8. 


\section{Trajetórias Relacionais e Reprodutivas Conducentes à Gravidez na Adolescência: a Realidade Nacional e Regional Portuguesa}

Acta Med Port 2014:27:543-555

Publicado pela Acta Médica Portuguesa, a Revista Científica da Ordem dos Médicos

Av. Almirante Gago Coutinho, 151

1749-084 Lisboa, Portugal.

Tel: +351 218428215

E-mail: submissao@actamedicaportuguesa.com

www.actamedicaportuguesa.com

ISSN:0870-399X | e-ISSN: 1646-0758

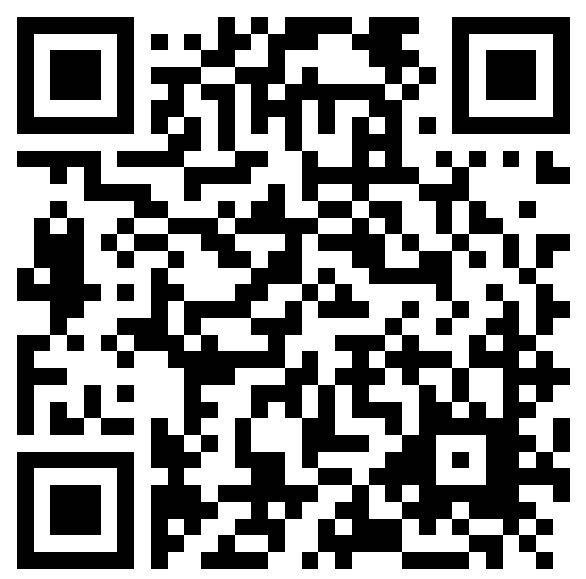

